\title{
THE SEPARATION WALL EFFECT OF A VOLUTE TWIN ENTRY CROSS SECTION AREA ON THE MIXED INFLOW TURBINE PERFORMANCE
}

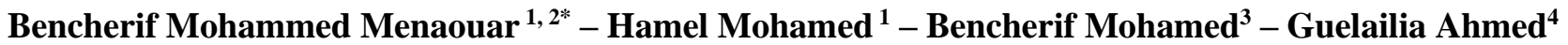 \\ - Hamidou Mohamed Kamel ${ }^{2}$
}

\begin{abstract}
${ }^{1}$ École Nationale Polytechnique d'Oran Maurice Audin, Route d'Es-Sénia, Oran, B.P. 1523 El M'Naouer 31000 - Oran, Algérie

${ }^{2}$ Laboratory of Applied Mechanics, Faculty of Mechanical Engineering, University of Science and technology Mohamed Boudiaf

${ }^{3}$ University of Science and Technology Mohammed Boudiaf, BP 1505, El M'Naouer 31000 - Oran, Algérie

${ }^{4}$ Centre of Satellite Development (CDS), Space Mechanical Research Department, BP 4065 Ibn Rochd USTO Oran, Algeria
\end{abstract}

\begin{tabular}{l} 
ARTICLE INFO \\
\hline Article history: \\
Received: 2.12 .2018$. \\
Received in revised form: 16.7 .2019$. \\
Accepted: 2.8 .2019$. \\
\hline Keywords: \\
The Twin entry mixed flow turbine \\
Pulse turbocharging \\
Unsteady flow \\
Mixed turbines \\
\hline DOI: https://doi.org/10.30765/er.1383
\end{tabular}

\begin{abstract}
:
The pulse turbocharging system is used in many diesel engines and it is fortunate that nozzleless mixed turbines allow unsteady flow with less performance losses. It operates with a double or sometimes triple-entry casing creating different flow regimes in each sector. A nozzleless casing is used. The division of the crosssection area takes the form of a solid wall in the radial plane. When the flow rate through one or the other volute inlet drops to zero, some reverse flow is observed from the other inlet. This situation suffers undesirable effects, diminishing the benefits of the divided volute casing types. A numerical investigation on the effect of the length of the dividing wall in the radial plane is performed using the ANSYS code. This possibility is explored and the results show that extending the wall to a limiting length enhances the flow behavior with better performance.
\end{abstract}

\section{Introduction}

Realizing the growing importance and availability of motor vehicles, which operate over the wide range of speeds and loads, it is desirable to use the pulse turbocharging system with a twin-entry volute. The benefits inherent in this type of divided casing usually outweigh the disadvantages, since some interference in flow between one inlet branch and the other one occurs. Some reverse flow appears, affecting the turbine performance. The tendency of the flow to reverse from one volute cross section to the other one, having in mind the unsteady flow conditions, with a phase difference between flow inlets, has given rise to consideration of the optimal wall division length and curvature. A numerical simulation is performed on the geometric modification of the twin entry volute cross section area. The results could replicate the behavior of the turbine pulsating flow with the advantage of full access to the flow data within the stage. Despite its importance, there are not many research activities in the area of twin-entry turbocharger turbines, and little detailed performance data is available in the open literature. Almost all research in this area is experimental. The turbine wheel used for all the tests is a mixed flow type. This wheel was designed at Imperial College by Abidat $[1,2]$ and to keep it consistent with the previously reported results, the wheel is referred to as a rotor " $A$ ". The main geometrical parameters are given in Table 1. Abidat et al. [3] proposed a method to predict the performance of a mixed flow turbine under both steady and unsteady conditions. The experimental results of Hajilouy et al [4] show that a maximum efficiency occurs at equal admission and the lowest efficiency is observed when the whole flow is in the inner limb. Chen et al [5] described the simulation

\footnotetext{
* Corresponding author

E-mail address: mohamed_benchrif@yahoo.fr
} 
results of a mixed flow turbine with a model of a volute considered as a tapered duct with one-dimensional unsteady flow analysis applied to this duct. Zine et al [6] present a numerical performance prediction of two mixed flow turbine rotors under the inlet steady flow conditions. The analysis underlines the benefits of the blade with forward sweep at the inlet, resulting in peak efficiency over higher expansion ratio or lower velocity ratio. Litim et al [7] studied the effect of the blade number on the performance of the mixed flow turbine. Mahfoudh et al [8,9] presented the aerodynamic behaviors of a twin-entry radial inflow turbine. Their results revealed the existing rotor and tongue potential effects and interaction effects of the rotor and volute. In addition to the circumferential and spanwise flow, non-uniformity at the volute exit, which are more accentuated with a pulsating flow at the inlet. The steady and unsteady performance of two mixed-flow turbocharger turbine rotors has been investigated by Hakeem I et al [10]. A detailed assessment of the volute geometry influence on the turbine performance has been carried out, which confirmed that the volute geometry plays a critical role in the overall performance of a turbine. Payri et al [11] proposed a physical model to calculate the fluid-dynamic behavior and energy conversion of two turbines. The first one is a singleentry turbine and the second one is a twin-entry turbine. Chiong et al [12] develop five onedimensional models of increasing complexity to study the geometrical effects on flow performance prediction under the full admission. Padzillah et al [13] presented the development efforts and results from a full 3-D CFD model of a turbocharger turbine stage into the turbocharger turbine design. Bencherif et al [14] studied the unsteady performance of a twin-entry mixed flow turbine. The results show that the twin-entry turbine exhibits greater filling and emptying characteristics with the application of a symmetrical twin-entry volute design, enhancing the performance of the turbocharger and engine. Hamel et al [15] focused on the performance predictions of a turbocharger twin-entry mixed inflow turbine. Their results show that the twinentry turbine provides the best compromise in terms of performances at different pressure ratio and significant increase in swallowing capacity. The investigation of Meghnine et al [16] on volute crosssectional shape of mixed inflow turbine reveals that flattened volute cross section in the radial direction achieves significant Mach number values reaching the highest swallowing capacity.

This paper presents the development of a new twin-entry turbine volute design shown on Figure 1. The ICEM tool is used to build the full turbine geometry and to generate the mesh while computational tests are performed with the ANSYS-CFX software. The comparison in performances between the new and the old configuration of the cross section area is undertaken. Both turbines are tested under equal additions (same pressure ratio within the turbine inlets) and unequal admission (unbalance of pressure ratio between the inlets).

In order to have a better interpretation of the phenomena governing the flow upstream of the rotor one must evaluate the flow pulses in the turbine. Several cross-sectional areas related to different azimuth angles are selected, in order to show the pressure effect on the two admission channels of the turbine.

Table 1. Turbine geometry.

\begin{tabular}{|c|c|}
\hline Rotor inlet mean diameter & $83.58 \times 10^{-3} \mathrm{~m}$ \\
\hline Rotor inlet blade height & $17.99 \times 10^{-3} \mathrm{~m}$ \\
\hline Rotor inlet blade angle & $20.0^{\circ}$ \\
\hline Rotor inlet cone angle & $40.0^{\circ}$ \\
\hline Exducer hub diameter & $27.07 \times 10^{-3} \mathrm{~m}$ \\
\hline Exducer shroud diameter & $78.65 \times 10^{-3} \mathrm{~m}$ \\
\hline Rotor exit mean blade angle & $-52.0^{\circ}$ \\
\hline Rotor axial length & $40.00 \times 10^{-3} \mathrm{~m}$ \\
\hline Number of blades & 12 \\
\hline Radial and axial tip clearance & $0.40 \times 10^{-3} \mathrm{~m}$ \\
\hline
\end{tabular}




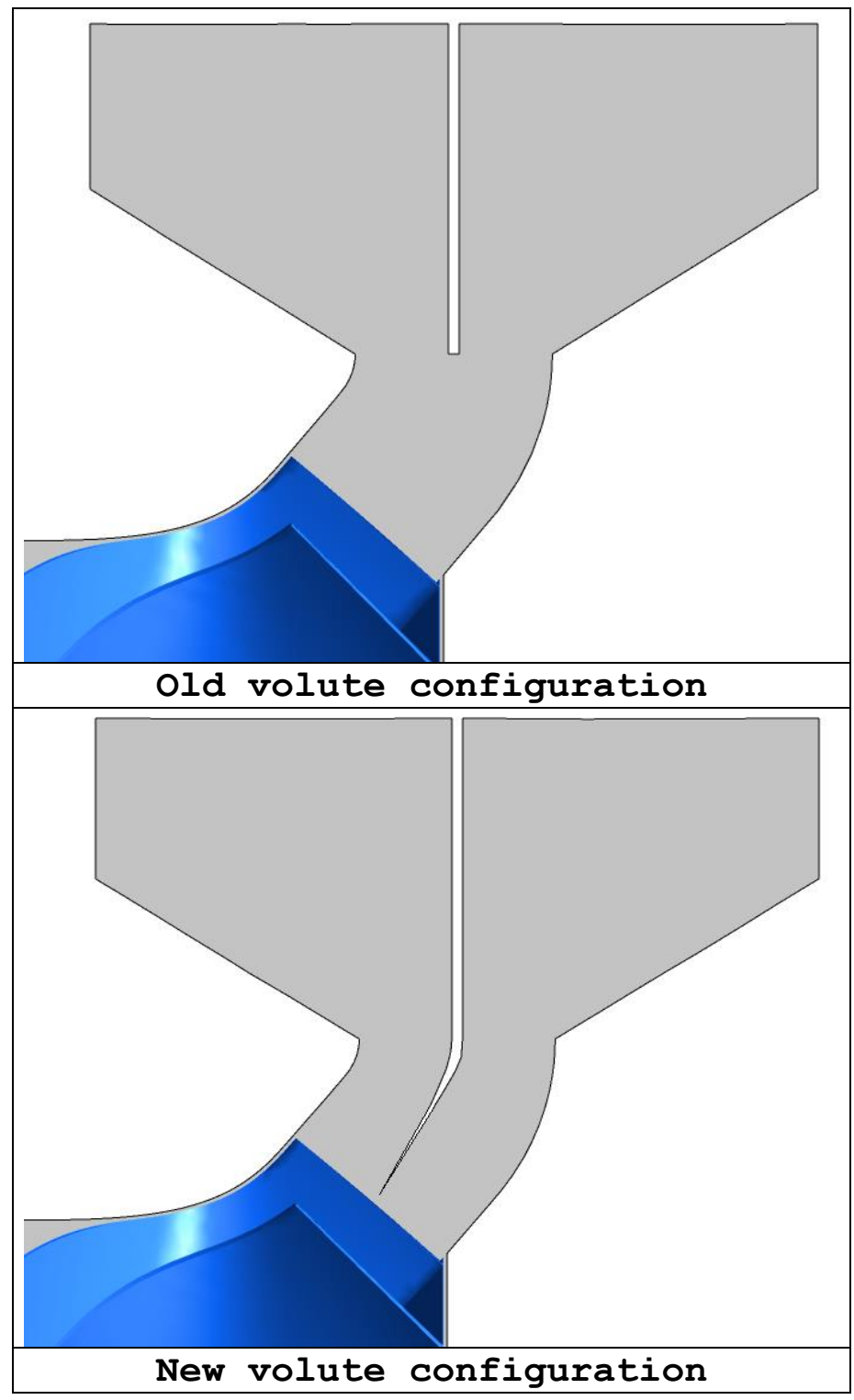

Figure 1. The cross section of the new and the old volute.

\section{Numerical methods}

The ANSYS-CFX-Solver was used to solve the 3D Reynolds-stress-averaged Navier-Stokes equations with mass-averaged velocity and time-averaged density, pressure and energy. Temperature, pressure and density are related by the equation of the state. The turbulence is modeled by the standard k- $\varepsilon$ equation of Patankar and Spalding [17]. This model is based on the eddy viscosity concept in which Reynolds stresses are expressed by the mean velocity gradients and the turbulent viscosity in an analogous way to the viscous stresses for laminar Newtonian flows. The highly three dimensional, viscous and compressible flow field is obtained by solving numerically the Reynolds average equations of mass, momentum and energy conservation. The approach adopted is the finite volume method. The terms of a partial differential equation system applied on the volume interfaces are discretized using a first or a second order upwind scheme. Simulations are firstly performed with the first order scheme. Then, the solution is predicted using boundary conditions and the first order scheme solution linear interpolation. Pressure-velocity coupling is achieved using a coupled solver. Flow is assumed to be subsonic at the inlet mixed flow turbine. Total pressure, total temperature and medium value of 5\% turbulence intensity are imposed in the stationary frame of reference, as well as on the flow direction. At the inlet boundaries, turbulence quantities are obtained with the inlet 
hydraulic diameter and the intensity of turbulence. The static pressure is imposed at the turbine outlet and no slip condition is defined at solid boundaries.

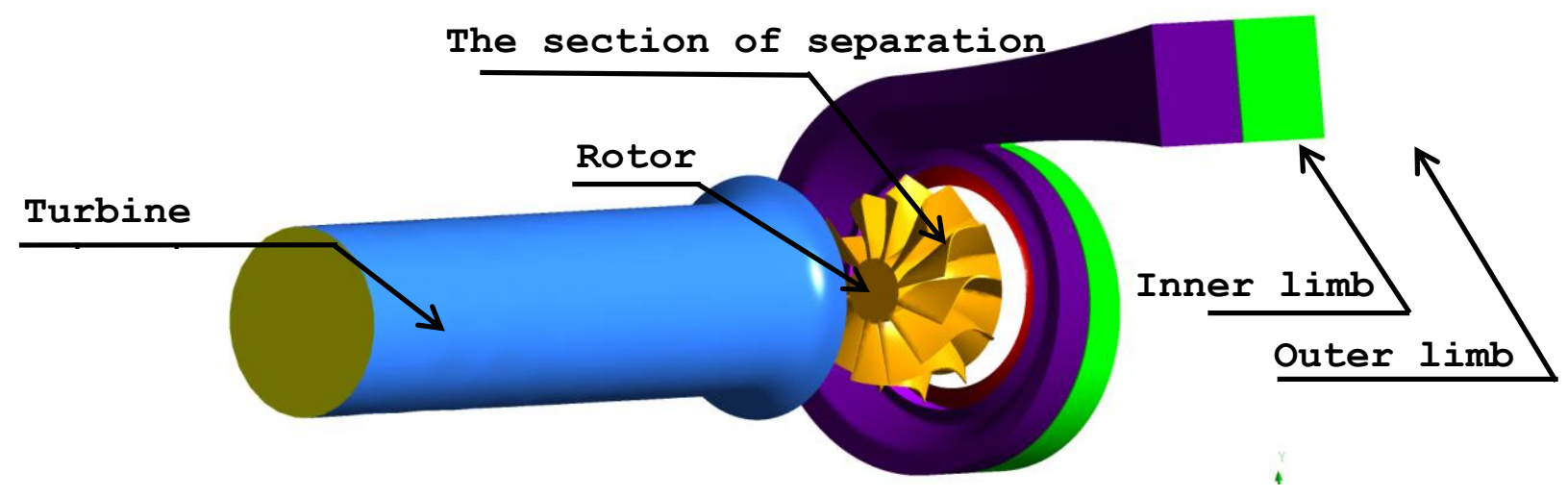

Figure 2. The Twin entry mixed flow turbine.

\subsection{Governing equations}

The mass conservation equation

$$
\frac{\partial \rho}{\partial \mathrm{t}}+\nabla \bullet(\rho U)=0
$$

where $\rho$ is the density and $U$ is the mean velocity vector.

The momentum conservation equations

$$
\frac{\partial(\rho U)}{\partial \mathrm{t}}+\nabla \bullet(\rho U \otimes U)=\nabla \bullet(-p \delta+\tau-\rho \overline{\mathrm{u} \otimes \mathrm{u}})+\mathrm{S}_{\mathrm{M}}
$$

where $S_{M}$ is the source term comprising body, Coriolis and centrifugal forces. $\mu_{\text {eff }}=\mu+\mu_{t}$ is the effective viscosity. $\mu_{t}=c_{\mu} \rho k^{2} / \varepsilon$ is the turbulent viscosity. $p$ is a modified pressure defined as

$$
P^{\prime}=P^{\prime}+\frac{2}{3} \rho K+\frac{2}{3} \mu_{e f f} \frac{\partial u_{k}}{\partial x_{k}}
$$

The energy conservation equation

$$
\frac{\partial h_{t o t}}{\partial t}+\nabla \bullet\left(\rho H h_{t o t}+\rho \overline{u h}-\lambda \nabla T\right)=\frac{\partial P}{\partial T}
$$

with the mean total enthalpy $H$ expressed as $H=h_{s}+U^{2} / 2+k$, where $h_{s}$ is the mean static enthalpy, $\lambda$ is the thermal conductivity, $T$ is the mean static temperature, and $k$ is the turbulent kinetic energy defined as $k=u^{2} / 2$

\subsection{Performance parameters}

Pressure ratio: 


$$
P_{r}=\frac{P_{0^{*}}}{P_{4}}
$$

Velocity ratio:

$$
\frac{\mathrm{U}_{2}}{C_{i s}}=\frac{\omega r_{2}}{\sqrt{2 C_{P} T_{0^{*}}\left[1-\frac{P_{4}}{P_{0^{*}}}\right]^{\frac{\gamma-1}{\gamma}}}}
$$

Total to static efficiency:

$$
\eta_{t s}=\frac{\left(h_{0^{*}}-h_{4}\right)}{C_{p}-T_{0^{*}}\left[1-\frac{P_{4}}{P_{0^{*}}}\right]^{\frac{\gamma-1}{\gamma}}}
$$

Where the stations: 0 is volute inlet, 2 is rotor inlet, 4 is turbine exit and $0 *$ is volute inlet stagnation condition.

\subsection{Mesh Generation}

The physical domain is discretized into finite volumes of tetrahedral elements as shown in Figure 3. The distribution of nodes within each domain as well as the final assembly of a twin-entry mixed flow turbine can be shown in Table 2. The ICEM CFD software is used to build the turbine geometry and to generate the unstructured mesh. The differential equations are approximated by a set of the algebraic equation system in this collection which is then treated to produce a set of discrete values in order to approximate the solution of the partial differential system over the numerical domain. In order to obtain a proper resolution of the boundary layer the first grid spacing refinement near the walls has been achieved during the mesh generation process. Indeed, the complexity of these regions has an important impact on the numerical solution determination, where the grid must be much more refined in order to capture the maximum informations. Otherwise, it is advised by the CFD code developers that the $y+$ value for the near wall nodes must be in the range of 20 to 100. This is actually a result of the use of the wall function approach to model the flow near wall boundaries using the $k-\varepsilon$ turbulence model.

Table 2. Mesh Information.

\begin{tabular}{|l|l|l|}
\hline Domain & Nodes & Elements \\
\hline Rotor domain & 204439 & 779844 \\
\hline Volute inner inlet & 132531 & 318000 \\
\hline Volute outer inlet & 142123 & 337810 \\
\hline Total & 479093 & 1435654 \\
\hline
\end{tabular}




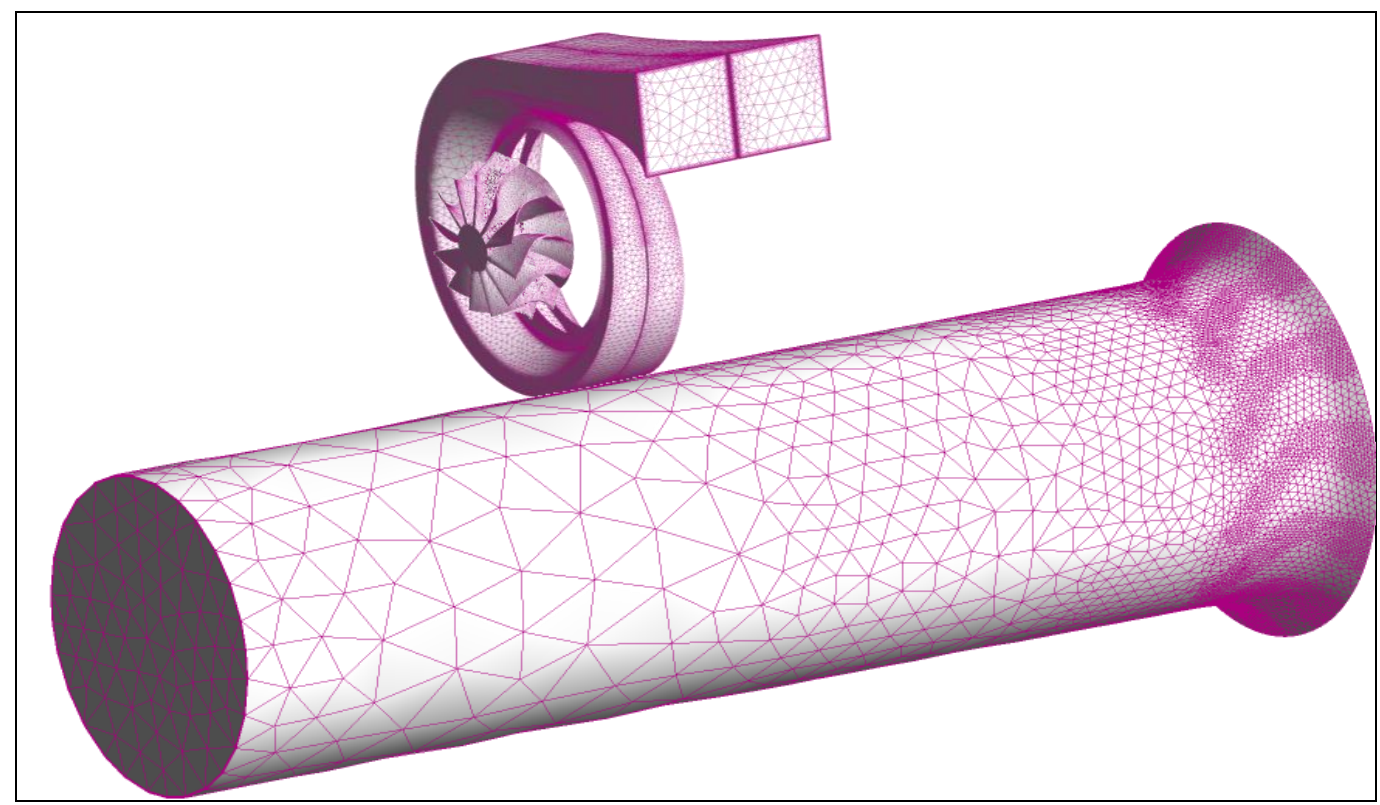

Figure 3. Computational grid of the twin-entry mixed flow turbine.

\section{Equal admission, results and discussion}

The predicted and experimental results under equal admission swallowing capacity data for the new and the old configuration of the mixed flow turbine are presented in Figure 4 and 5. Steady state turbine performances are obtained by measuring required parameters such as the static pressure, static temperature and turbine speed at the turbine inlet. Steady simulations were performed at constant speed with a varying pressure ratio range between 1.9 and 3, 3 at 100\% relative speed, which corresponds to a shaft speed of $59,740 \mathrm{rpm}$ at full admission conditions. The comparison between the numerical and experimental results of the total to static efficiency versus the expansion ratio shown in Figure 4 and the pressure ratio along to the axial direction shown in Figure 4, reveal good agreements in the case of equal admission. The effect of the new geometry is not pronounced at all. The experimental results are given by Abidat et al [1]. The mixed flow turbine shroud pressure distribution, is represented along the blade axial direction, this type of pressure distribution corresponds to an accelerating stream through the turbine and decelerating stream at the exit (diffuser). In the case of equal admission there is no need to use a longer wall in the radial plane for cross section area division, since reverse flow are not present and the efficiency is not affected.

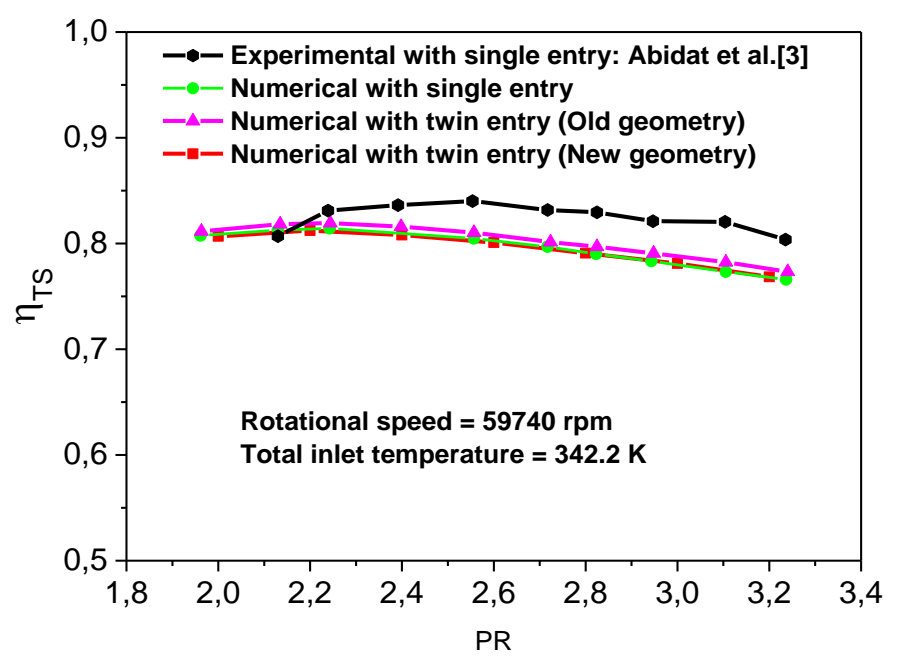

Figure 4. Predicted and experimental turbine efficiencies versus pressure ratio. 


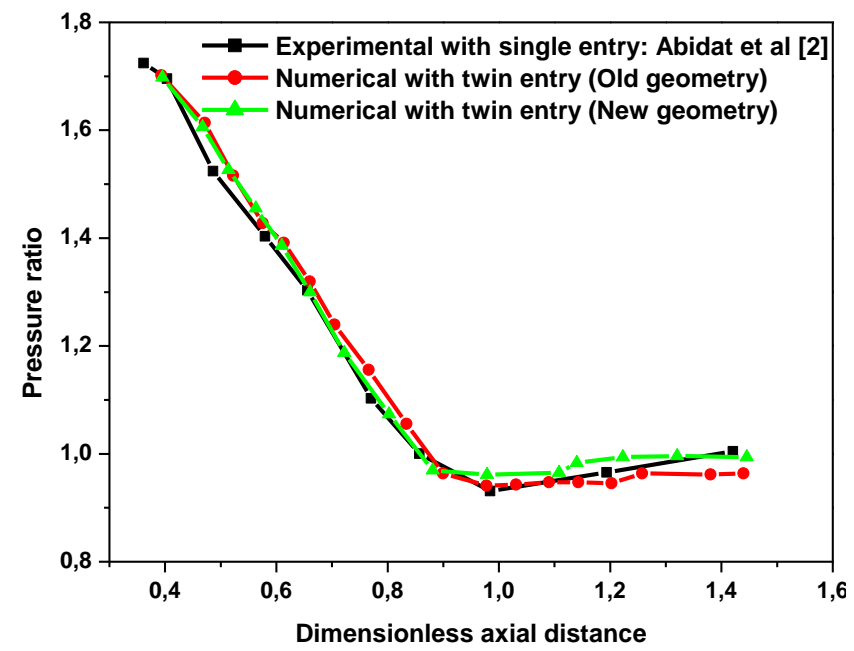

Figure 5. Turbine shroud pressure ratio axial distribution.

\section{Unequal admission, results and discussion}

The unequal admission results for the new and the old configuration of the turbine under a pulsating flow are performed at $100 \%$ of the relative speed which corresponds to a shaft speed equal to $59,740 \mathrm{rpm}$. The inlet turbine total temperature is kept with a constant value of $342,2 \mathrm{~K}$. It is of interest to investigate the effect of the difference between the inner inlet and the outlet inlet pressure ratio $(\Delta p)$. In order to accomplish this, a range of differences $(\Delta \mathrm{p})$ is adopted for the simulation, namely: $\left(P_{\text {inner }}=1.3\right.$ and $\left.P_{\text {outer }}=1.4\right)$ with $\Delta p=0.1$ and $\left(P_{\text {inner }}=1.3\right.$ and $\left.P_{\text {outer }}=2\right)$ with $\Delta p=0.7$.

The Figure 6 indicates the efficiency curves for both turbine types. It is observed that the new volute twin entry presents a much better efficiency profile curve. The maximum discrepancy is around $29 \%$.

On account of this, uniformity of the Mach number distribution and the pressure distribution is achieved along the azimuth angle presented respectively in Figure 7, 8 and 9, 10.

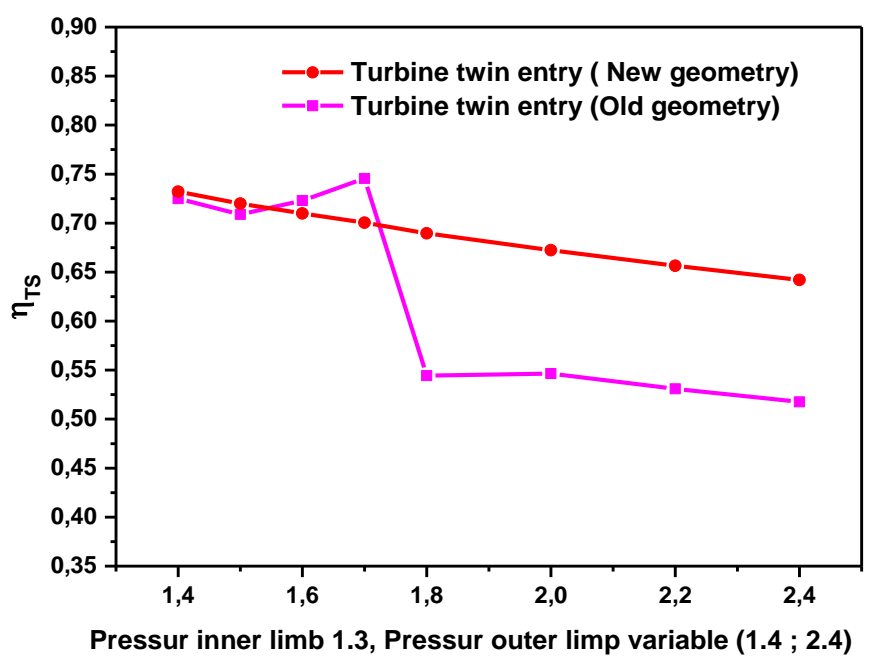

Figure 6. Turbine efficiency versus pressure ratio with unequal different pressure ratio admission (inner inlet 1.3 and outer inlet 1.4). 


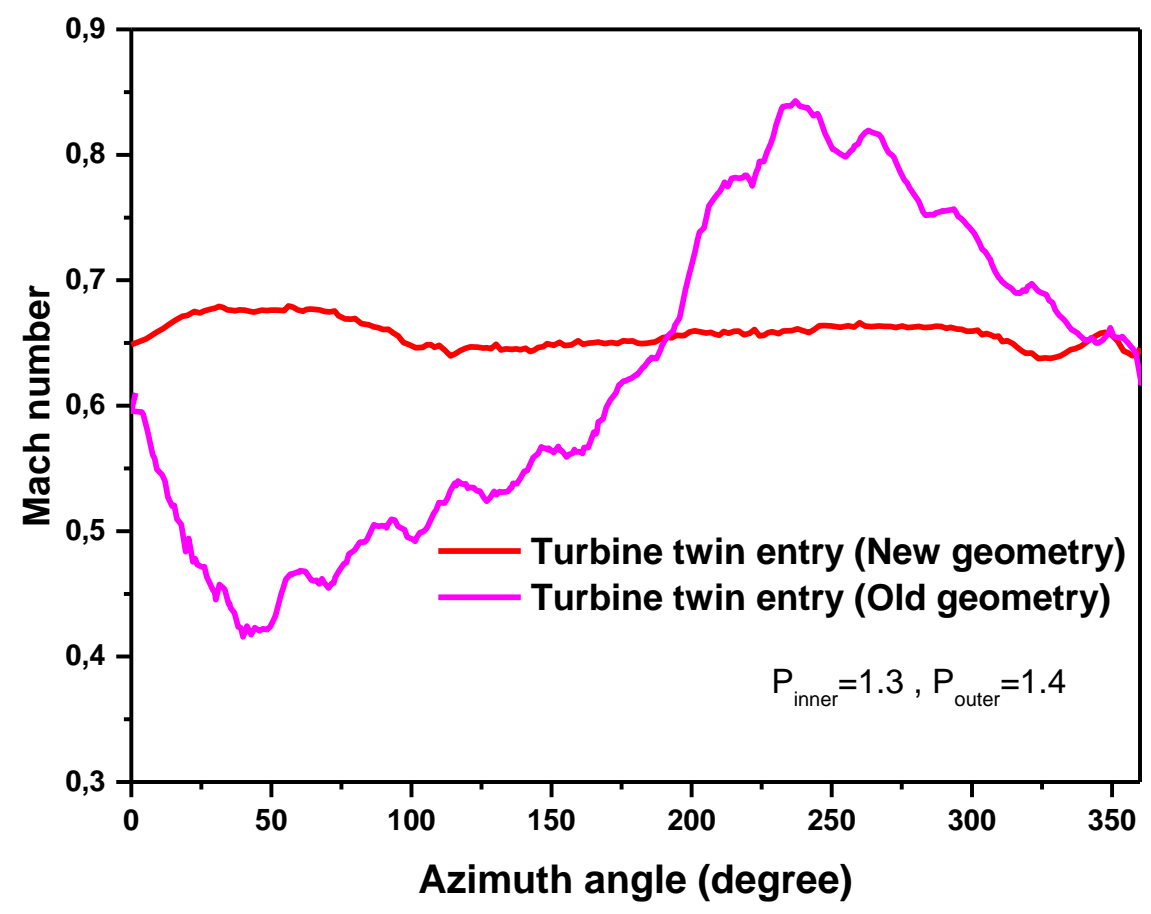

Figure 7. Distribution of the Mach number versus azimuth angle with different pressure ratio inlet (inner inlet 1.3 and outer inlet 1.4).

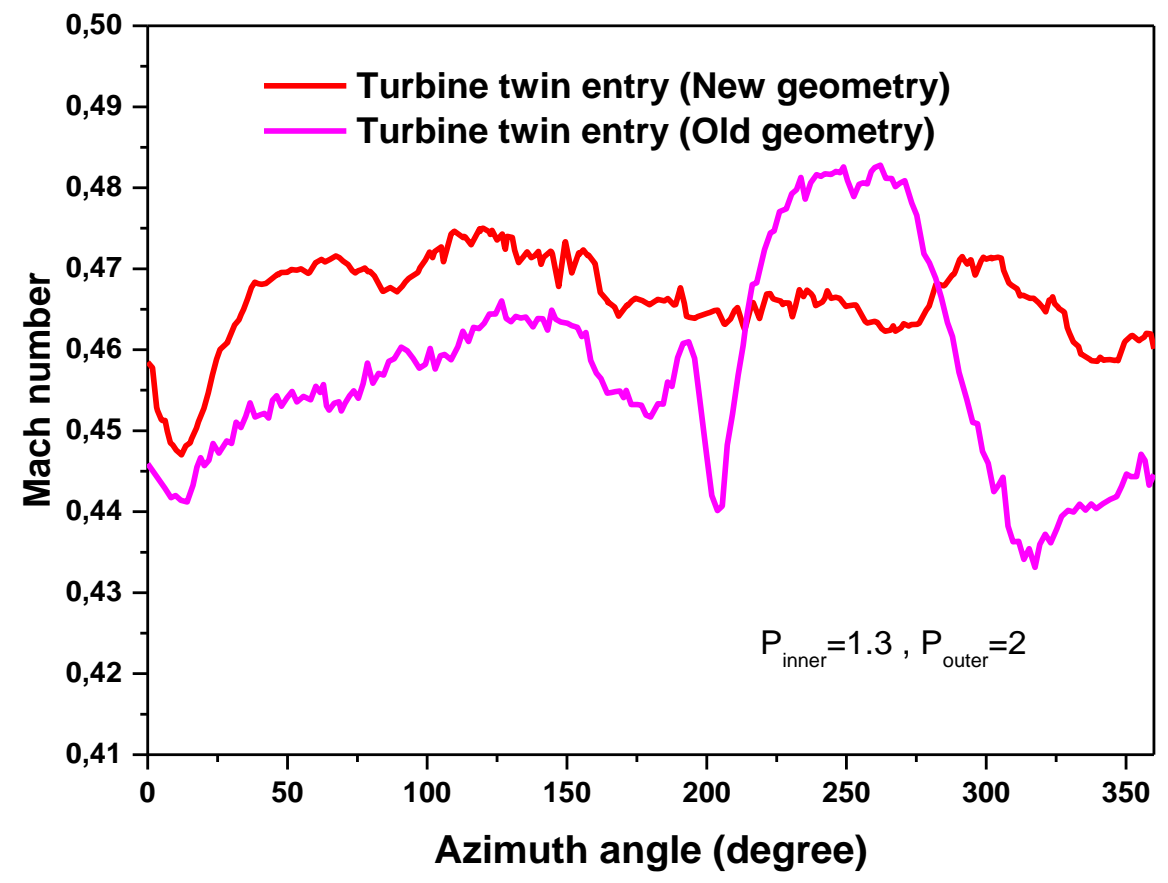

Figure 8. Distribution of the Mach number versus azimuth angle with different pressure ratio inlet (inner inlet 1.3 and outer inlet 2 ). 


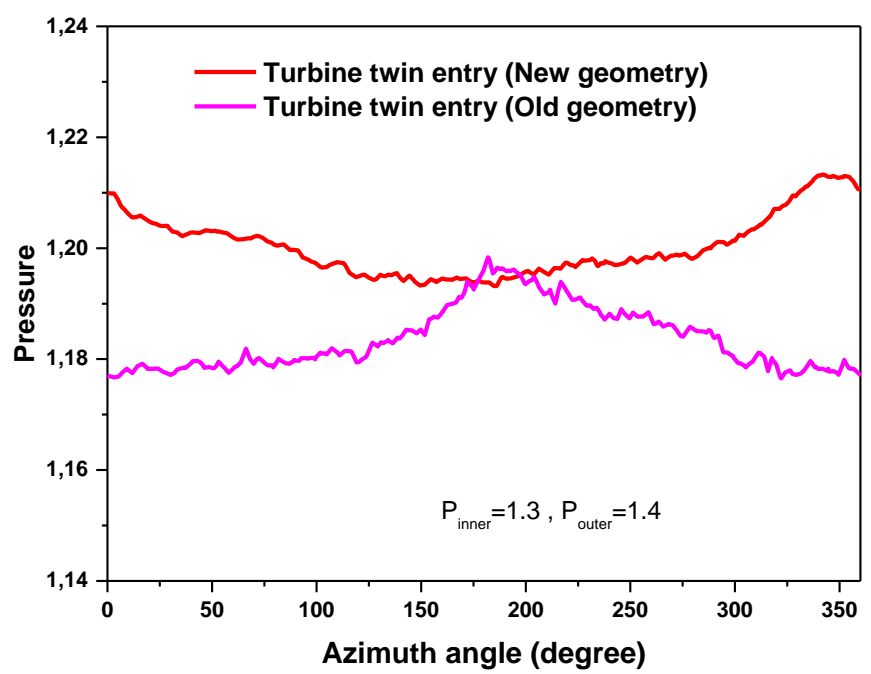

Figure 9. Distribution of the pressure ratio versus azimuth angle with different pressure ratio inlet (inner inlet 1.3 and outer inlet 1.4).

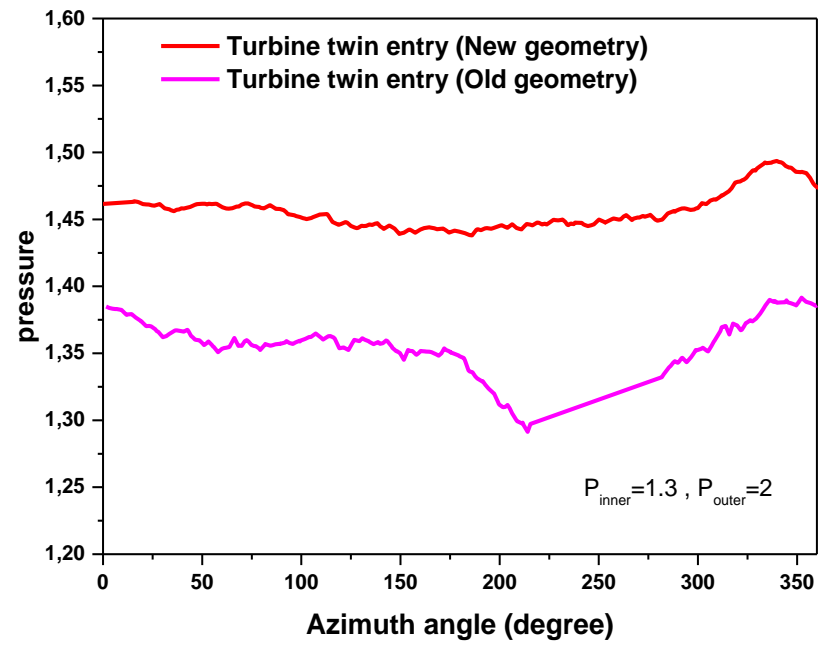

Figure 10. Distribution of pressure versus azimuth angle with different pressure ratio inlet (inner inlet 1.3 and outer inlet 2).

It is clear that unsteady 3D numerical simulations allow us to study the detailed flow structure through a perpendicular passage to the tangential direction within the volute. In the attempt to have additional explanations about the physical phenomena governing the flow upstream the rotor several series of crosssectional area are presented. Unequal admission pressure ratio between inner and outer limb are applied to the old volute geometry and to the one with a longer dividing cross section wall. Figure 11 illustrates velocity distribution at three different azimuth angles $\left(0^{\circ}, 180^{\circ}\right.$ and $\left.270^{\circ}\right)$ for both vaneless volutes. These results may indicate that a longer separating wall between the two cross section areas of the volute entrance, is suited to use in other to overcome the reverse flow problem. The interference phenomena between one inlet branch and the other one which causes the fall out of the efficiency will be damped out. The Figure 12 illustrates the effect of different $\Delta p$ on the flow field configuration. In the case of the old volute, the simulation results show evidence of strong reverse flows once the difference $\Delta p$ exceeds 0.3 . A longer separating wall stays unaffected by this reverse flow problem. In addition, the jump on the efficiency curve in Figure 6 is eliminated. 


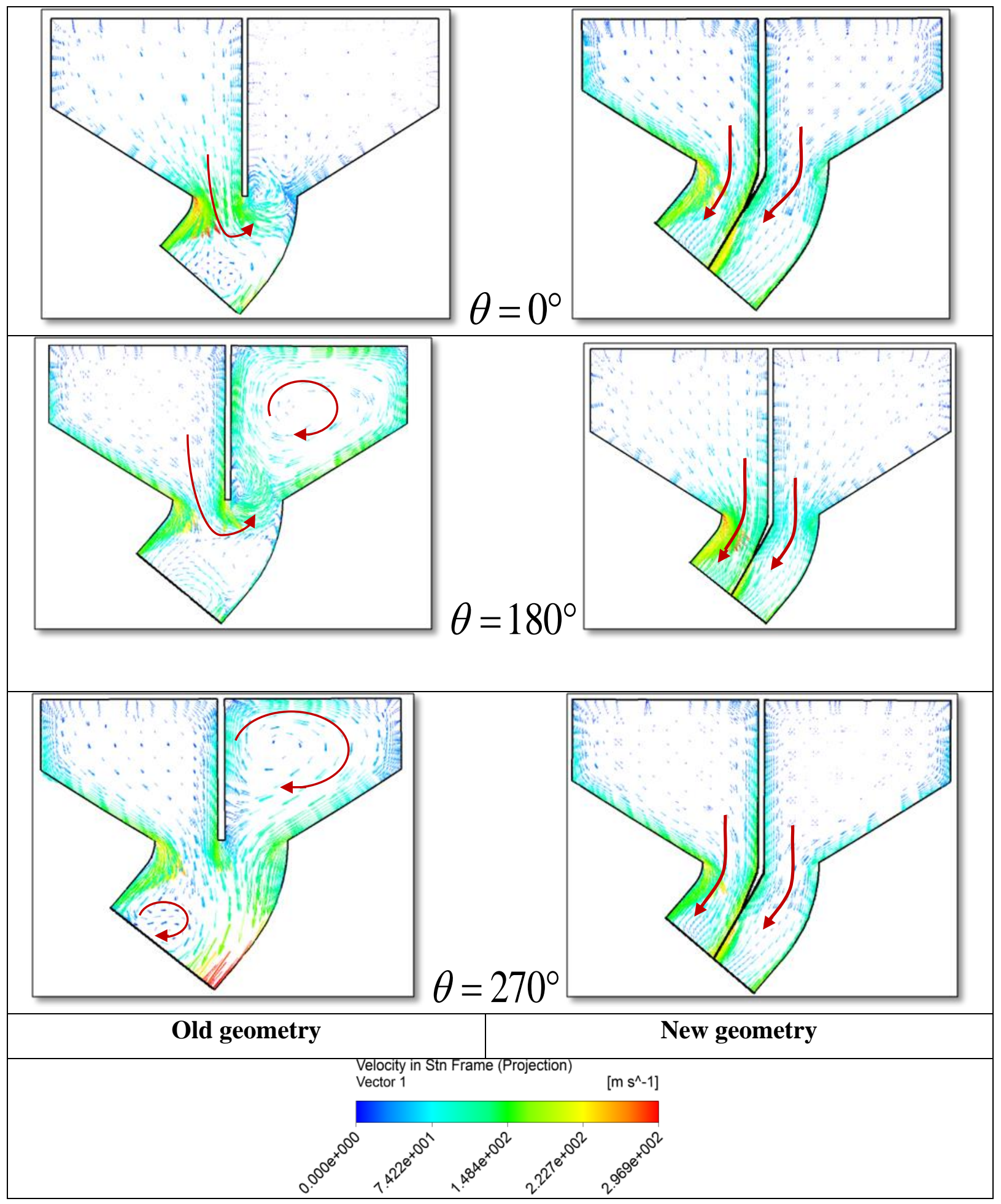

Figure 11. Distribution of the velocity versus azimuth angle with unequal inlet pressure ratio (inner inlet 1.3 and outer inlet 2). 


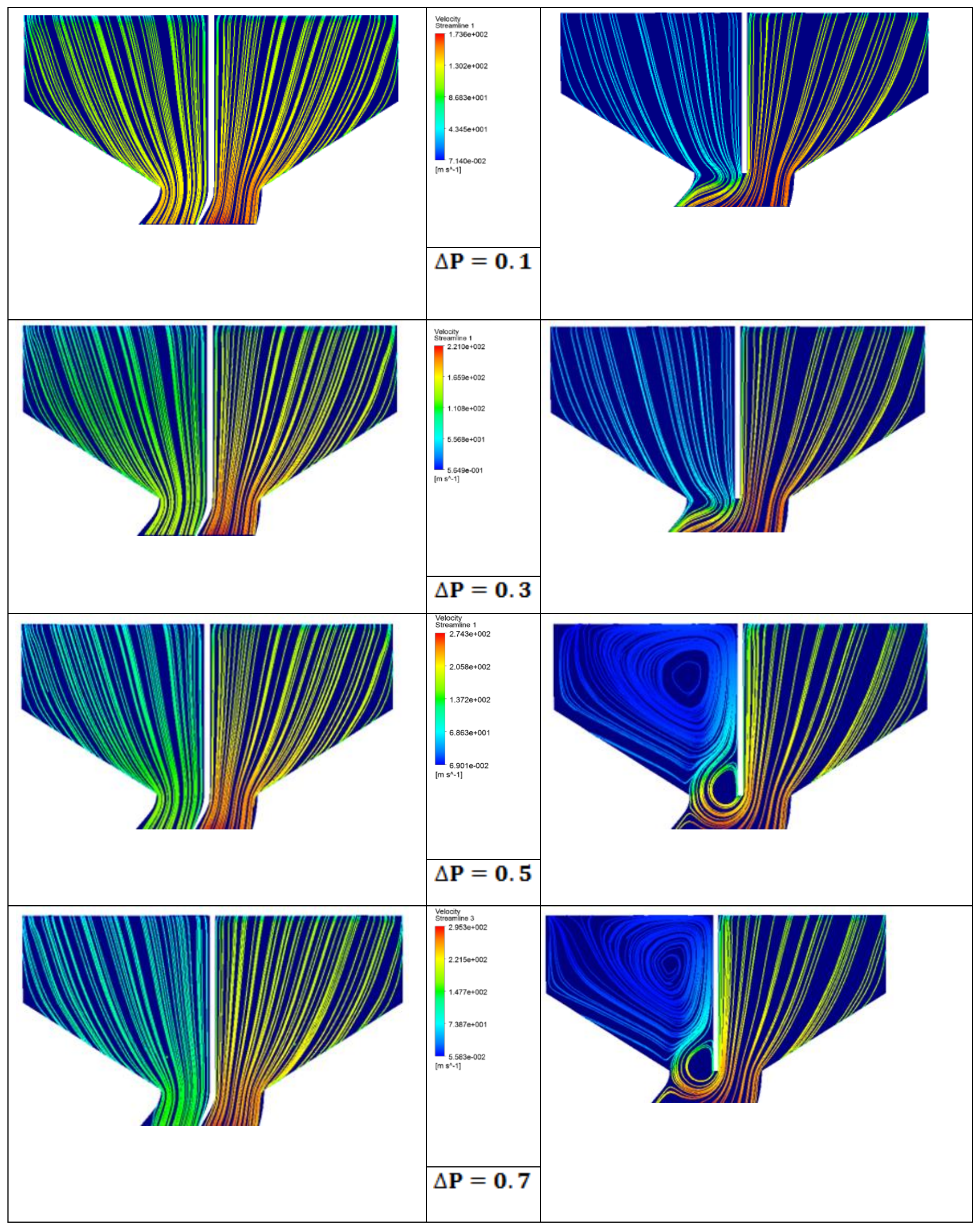

Figure 12. Streamline configurations in the volute cross section with the different pressure ratio between the inner and the outer inlet turbine. 


\section{Conclusion}

The present paper is an attempt to design a volute twin entry cross section with a longer separating wall, in order to discard any reverse flow formation which represents a source of turbine performance degradation due to severe losses in the pulsating flow regimes. The latter arises as a case of particular interest. The effect of changing the pressure difference between the inner and the outer exit cross section of the twin entry volute is investigated. The results of the numerical analyses reveal that in the case of the old geometrical configuration, the reverse flow appears from pressure differences exceeding 0.3 . The main feature of the new volute cross section configuration might simply be the avoidance of local flow reversal. The jump indicated on the efficiency curve for the old cross section area is eliminated in the case of the new proposed cross section geometry, with a maximum discrepancy of $29 \%$ in efficiency and $7.09 \%$ in pressure. Apparently, the benefit acquired; such as uniformity of the efficiency, the Mach number and the pressure distribution; overcomes the penalty incurred, which would be expected to be due to a large wall friction inducing additional friction losses but with a better flow guidance. The objective of this study is to give the designer an appreciation of certain flow feature benefits linked with the use of a larger separating wall in the radial direction, enhancing the mixed turbine performance.

\section{References}

[1] Abidat, M.: Design and Testing of a Highly Loaded Mixed-Flow Turbine, PhD Thesis Imperial College of Sci Technol and Medicine, University of London, London, 1991.

[2] Abidat, M., Chen, H., Baines, N. C.: Design of a Highly Loaded Mixed Flow Turbine, Proc IMechE, Part A. J Power and Energy, 21 (1992), 206, pp.95-107.

[3] Abidat, M., Hachemi, M., Hamidou, M. K., Baines, N. C.: Prediction of the Steady and Non-Steady Flow Performance of a Highly Mixed-Flow Turbine. Proc IMechE Part A J Power and Energy 212 (1998), pp.173-183.

[4] Hajilouy, B. A., Rad, M., Shahhosseini, R.: Flow and performance characteristics of twin-entry radial turbine under full and extreme partial admission conditions, Arch. Appl. Mech, 79 (2009), pp. $1127-$ 1143.

[5] Chen. H., Hakeem. I., Martinez-Botas, R. F.: Modelling of a turbocharger turbine under pulsating inlet conditions. Proc IMechE Part A: J Power and Energy, 210 (1996): pp. 397-408.

[6] Zine, K. O., Hamel M., Hamidou, M. K.: Computational aerodynamic performance of mixed-flow turbine blade design, Engineering Review, 37 (2017), pp. 201-213.

[7] Litim, S., Hamel, M., Hamidou M. K., The number of blade effects on the performance of a mixed turbine rotor, Engineering Review, 37 (2017), pp. 349-360.

[8] Mahfoudh, C., Adel, G.: Analyses of steady and unsteady flows in a turbocharger's radial turbine, Proc IMechE Part E. J Process Mechanical Engineering, 01 (2015), pp. 1-16.

[9] Cerdoun, M., Ghenaiet, A.: CFD analyses of a radial inflow turbine. In: IMechE. 8th international conference on compressors and their systems, (2013), pp. 635-647.

[10] Hakeem I., Su, C.C., Costall, A., Martinez-Botas, R. F.: Effect of volute geometry on the steady and unsteady performance of mixed-flow turbines. Proc IMechE, Part A. J Power and Energy, 221 (2007), p. 535-549.

[11] Payri, F., Benajes, J Reyes, M.: Modeling of supercharger turbines in internal combustion engines, Int. J. Mech. Sci, 38 (1996), pp. 853-869.

[12] Chiong, M. S., Rajoo, S., Martinez, B. F., Costall, A. W.: Engine Turbocharger Performance Prediction One Dimensional Modeling of a Twin Entry Turbine, Energy Convers Management 57 (2012), pp. 68-78.

[13] Padzillah, M. H., Rajoo, S., Martinez, B. R. F.: Influence of speed and frequency towards the automotive turbocharger turbine performance under pulsating flow conditions. Energy Conversion and Management 80 (2014), pp. 416-428.

[14] Bencherif, M. M., Hamidou, M. K., Hamel, M., Abidat, M.: Study of unsteady performance of a twinentry mixed flow turbine, Journal of Applied Mechanics and Technical Physics 57 (2016), pp. 300307.

[15] Hamel, M., Bencherif M M., Hamidou M K.: Investigation of a Twin Entry Mixed Flow Turbine Volute, Benefits with Regard To the Eco-System, J. Materials Physics and Mechanics 32 (2017): pp. 
$31-42$

[16] Meghnine, M A., Hamidou, M K., Hamel, M.: Influence of the volute cross-sectional shape on mixed inflow turbine performances, Advances in Mechanical Engineering 9 (2017): pp. 1-1.

[17] Patankar, S V., Spalding, D B.; A Calculation Procedure for Heat, Mass and Momentum Transfer in Three-Dimensional Parabolic Flows, Int. J. Heat Mass Transfer 15 (1972): pp. 1778-1806. 